\title{
Atmospheric Intensities: Skin Conductance and the Collective Sensing Body
}

ELIZABETH DE FREITAS \& DAVID ROUSELL

\section{INTRODUCTION}

The first pages of Massumi's (1995) seminal article, "The Autonomy of Affect," describe a German psychological study of children's bodily responses while viewing a short film of a melting snowman on television. The study used a combination of biometric sensors to collect data on the children's breathing, heart rate, and electro-dermal skin activity $(\mathrm{EDA})^{1}$ while they watched different versions of the film (Sturm 1987). While increased arousal of breathing and heart rate was associated with the narrated version of the film, increased intensity of skin activity was associated with the silent version. The results of the study were perplexing, to the extent that they suggested a 'split' or gap between what Massumi calls "sociolinguistic qualification" of the narrated film, and the affective intensity captured in the EDA data( Massumi 2002, 24). The EDA sensors are said to register preconscious changes in the electrical conductivity of the skin, changes that are associated with arousal of the sympathetic nervous system. In Massumi's analysis, the study suggests that the play of affective intensity is "autonomous" or independent of the verbal account and, indeed, is dampened by the verbal overcoding of the film. This suggests that intensity operates through an alternative loop, logic, and temporality of experience that is "most directly manifested on the skin- at the surface of the body, at its interface with things ... It is narratively de-localized, spreading over the generalized body surface" (Massumi 1995, 85). 
Notably, the visual content of the film itself pertains to environmental dis/embodying processes in the shape of a melting snowperson who is rescued and repositioned in a colder environment where snowy-embodiment can be sustained. The narrative content draws attention to the dissipative and precarious existence of a body, as an unstable assembling of environment forces. The skin then becomes an interface for fielding a distributed intensity, rather than acting as boundary or container for personalized experience, and is irreducible to language or cognition:

\begin{abstract}
Indeed the skin occupies the quivering periphery of the 'bounded individual' that we take to be the mark of the organ/ism. The EDA skin data is thus perfect for showing how the bounded individual is always being broken down, disassembled, remade, intensified, and charged. Rather than treat synapse and society as disjunctive and antagonistic, one can use the EDA data as a way of tracking the blended world of the peripheral nervous system. At the juncture of the skin are mixtures of synapse, cilia, sweat, mind, and society, all percolating (de Freitas 2018, 299).
\end{abstract}

This chapter explores the creative and empirical potentials of EDA sensors for mapping the play of affective intensities across the environment. Building on the arguments formulated in de Freitas (2017b; 2018), and offering examples in response to her call for more creative work in this area, we focus on the use of wearable EDA sensors in participatory art and social inquiry with young people. We discuss creative experiments that brought young people together with artists and researchers to collectively explore their local environments through alternative practices of sensing, thinking, and making. ${ }^{2}$ In breaking away from clinical and pathologizing models which interpret electrical skin activity as a form of individual stimulus-response, our work reclaims EDA data as an atmospheric function of the environmental and the atmospheric. Specifically, our experiments aim to study the collective nature of becoming achieved through works of immersive art and media, in which multiple agents together achieve a shared but heterogeneous understanding of an event (Rousell \& Fell 2018). Rather than use the devices for identifying individual affect, we design experiments in which EDA signals from multiple bodies are fused and fed back into the environment. We assemble the concept of atmospheric intensity to describe affectively charged environments in which bodies and technologies enter into complex relations of sensory intermixing and dispersal. This entails a rethinking of sensation as environmentally 
distributed across events rather than tied to individual persons, opening up novel possibilities for mobilizing biosensory data through critical and creative modes of inquiry.

Our approach draws on the innovative insights of Elizabeth Wilson (2015), who reclaims the biochemical dimensions of the body in pursuing new forms of biosocial inquiry. We suggest that EDA sensors can operate as technical 'witnesses' to the circulation of affect and sensation within events, showing how the sympathetic nervous system is involved in intense eco-social contractions that take place above and below the thresholds of representational thought. In proposing an account of EDA sensors as both atmospheric and intensive, we foreground the ways that organic bodies and technologies shape and reshape one another within complex ecologies of sensation. We offer an example as to how artists and researchers might reclaim digital sensory data as a means of subverting the interests of a normative control society, showing how sensory data is implicated in complex operations that extend beyond the narrow bandwidth of the human senses. This work has become increasingly urgent as sensor technologies become ubiquitous elements of everyday life, opening up significant ethical and political questions regarding the capture and redistribution of sensory data.

\section{DATA CAPTURE/DATA DISPERSAL}

EDA technologies have an ethically checkered history of implementation within clinical laboratories over the last century, most recently used to document distraction and learning disability (Meloni et al. 2016). Recent advances in affective computing, neuro-marketing, and consumer technologies have made EDA-enabled wearable devices increasingly accessible to corporations, governments, and the general public. The rapid movement of EDA sensors from the laboratory into the public domain can be understood as a new layer in the relentless economization of life processes through the algorithmic capture of personal data (Massumi 2018). By capturing the otherwise invisible play of affective intensity on the surface of the skin, EDA data has the insidious potential to add preconscious data to existing behavioral and geolocative data profiles of individuals under corporate and governmental regimes (Banaee et al. 2013). In short, there is the dangerous possibility of 'mining intensity.' 
Such concerns motivate our engagement with children and young people around sensor technologies, and EDA sensors in particular, through collaborative research and artistic co-production (Rousell, Gallagher \& Wright 2018). Children and young people are particularly vulnerable to conditions of ubiquitous sensation and data mining currently being mobilised in various built environments, where passive data is taken without their knowing (de Freitas, Rousell \& Jäger 2019). This is exemplified in Intel's current smart classroom initiatives which aim to personalize learning environments through the collection of facial, gestural, emotional, and behavioural data. The Intel system uses biosocial sensors to create data profiles of students that can be immediately accessed by teachers, who are "armed with a dashboard providing real-time engagement analytics" (Intel 2019). As described on Intel's website, the system uses "the computing power of Intel CPUs to support artificial intelligence innovations with deep learning capabilities that can now know users at a higher level - not merely interpreting user commands but also understanding user behaviours and emotions" (Intel 2019). This example highlights the growing corporate investment in sensory technologies capable of collecting, processing, and analyzing biometric data to support governmental agendas through distributed mechanisms of surveillance and control (Deleuze 1992).

While there is a growing body of critical literature on these dangers (Gillborn 2016; Meloni 2016; Meloni et al. 2016; Williamson 2016), there is also a need for research that critically and creatively employs these devices in participatory experiments (Nold 2009; Papoulias \& Callard 2010; Rousell \& Diddams 2020). Such experiments could reclaim and repurpose EDA data, refusing to let it serve normative and controlling agendas. In that spirit, we aim here to show how EDA data might be understood as belonging to the environment first and foremost, as part of atmospheric affects, sensations, and intensities. In resisting the reductive and pathologizing discourses that have historically dominated the use of these technologies, we aim to steal EDA away from controlling regimes, and instead put the data into poetic circulation or errant wandering (Glissant 1997). This entails a politics of sensation that reconceptualizes such 'biodata' as part of the relational ecology rather than the individualized "quantified" body or self (Lupton 2014; Nafus 2016). Our contention is that the increased mobilization and accessibility of EDA sensors opens up new possibilities for and, indeed, demands reclaiming, recuperating, repurposing, and retheorizing biodata through ethically-driven creative experimentation. 
If the human subject is a kind of after-image of subpersonal material processes, what is the best way to 'make sense' of the virtual or intensive nature of these electrical charges as they flit across the wet surfaces of our bodies? If reductive scientisms turn to biosensors [...] to control the future, what kinds of experiments might we design to show how this intensity belongs to the learning environment? What kind of software analytics will help us analyze EDA data as ecological (de Freitas 2018, 308)?

As questions of presence and localism are reconfigured in light of sensor technologies, the issue of temporality is also foregrounded. How are we 'clocking' this kind of ecological experience? What is the current time it takes to catch a feeling (the time of contamination rather than exchange)? Sensory technologies operate at microtemporal scales that transit through the molecular and infraindividual, stretching the present moment across the transindividual event (de Freitas 2017a; 2019b). To the extent that time is stretched and packaged in new ways through sensory technologies, new forms of labor, exploit, and surplus value emerge within these 'augmented' milieus (Massumi 2018). How might we better understand the play of atmospheric intensity within these milieus, without resorting to reductive models of quantification?

Typical scientific studies of skin conductance maintain the individual organism as the unit of analysis, attributing causality to an external stimulus triggering an internal response that materializes on the surface of the skin under controlled conditions (Hernandez et al. 2014; Krieberg 2010). Individual results are aggregated and statistically analyzed to build a 'stepby-step' cognitive-behavioral model of emotional response to a particular stimulus, such as a film or image. Several empirical studies have recently departed from these conventional models, using EDA sensors to register degrees of sympathetic synchrony between bodies in everyday situations. In these studies, synchrony describes the preconscious resonance between EDA signals captured from multiple bodies simultaneously. These studies are of interest to us because they shift the unit of analysis from individual stimulus-response to complex ecologies of relational intensity and resonance. For instance, Slovák et al. (2014) conducted a study of 20 pairs of friends chatting in a local pub while wearing EDA sensors and GoPro body cameras. Their analysis focused on the interactional dynamics between pairs as mapped through degrees of synchrony defined as "mutual relation" between the raw EDA signals (Slovak et al 2014, 512). Their findings 
associated consistent and stable synchrony between bodies with high intensity engagement, while fluctuations and variations in synchrony were associated with low intensity engagement.

A related study by Kervonen et al. (2016) investigated what they term "embodied synchrony" between couples and co-therapists during relationship counseling sessions. They theorize embodied synchrony in terms of multi-actor attunements, emotional contagions, and "vitality affects" (Stern 1985), and acknowledge the variable speeds and modulations of affective attunement that take shape within the therapeutic context. Interestingly, the authors of this study chose to utilize only the tonic form of the EDA signal, which we define below, in conjunction with heart rate and respiration sensors. They documented time lags for tonic EDA synchrony, ranging from -7 to +7 seconds, in order to map the ways that one signal might 'follow' or mirror another. The results of this study suggested that EDA synchrony was the most consistent between co-therapists, and least consistent between couples.

As we seek experiments that dig into the somatic and affective dimension of ecological relationality, it is important to interrogate assumptions that synchrony is necessarily a public good. For instance, the study by Karvonen et al. (2016) highlights the disjunctive temporalities of embodied resonance rather than aiming for concordant simultaneity, while also questioning the desire for higher levels of intensity or consistencies of synchrony. Their study suggests that the redistribution and dissipation of intensity is often the core activity of therapeutic work, and that embodied synchrony is achieved less by dialogic 'face-to-face' interaction, and more by slow attunement to the atmospherics of the therapeutic event (Karvonen et al 2016, 383). We note that sympathetic coordination is a bodily struggle (Deleuze \& Guattari 1987). In that sense, sympathy is not a 'liking' affinity between individuals, but rather the forming of dependency relations in sympoiesis (de Freitas 2019a). This shifts the concept of resonance away from a coming together in homogeneity or sameness, toward a complex assembling of quivering differences that sustain complex socio-material ecologies. 


\section{ATMOSPHERIC MEDIA}

While the two studies cited above go some way toward articulating a relational approach to skin conductance, in our view they are limited by not embracing a more ecological perspective. Our recent experimentations with EDA sensors aim to develop an alternative empirical trajectory that takes the intensive atmosphere of a multi-sensory event as the unit of analysis. Our interest is not in individual response or intersubjective relations but, rather, in the fielding of impersonal atmospheric intensities that play across the charged surfaces of bodies. This approach sheds very different light on the significance of EDA data. One of the important drivers of this atmospheric reading of EDA data is the recognition that digital sensing technologies do most of their work outside the narrow bandwidth of human perception (Galloway \& Thacker 2007; Hansen 2015). In many cases, the technical operations that digital technologies use to sense, calculate, and mediate our environments do not correspond with human sense perception or cognitive capacities. In rereading Whitehead's philosophy through contemporary media studies, Hansen (2015) describes how twenty-first-century sensor technologies operate at micro-temporal processing speeds that take place above and below the thresholds of human consciousness and sense perception. Rather than being prosthetic extensions of human embodiment and perception, he describes how digital media technologies physically and directly shape the environment by altering its "causal infrastructure" and reconfiguring the conditions through which human sense experience becomes possible (Hansen 2015, 38). In this respect, digital sensing technologies "impact the environment - including our bodily environment - before impacting ... our higher-order sensory and perceptual faculties" (ibid.).

Digital sensing technologies are thus seen to mediate, reconfigure, and co-produce the atmospheric conditions through which experience takes shape. Through these devices, architectural walls, screens, and objects become animate, increasingly sensitive, and capable of mediating the molecular, biochemical, and semiotic 'trafficking' of data across the porous membranes of human bodies and cells (Frost 2016; Grönvall, Fritsch \& Vallgårda 2016). WiFi signals, for instance, pass through the walls of buildings and human tissue alike, respecting no fixed boundary between body and environment. As Parisi (2009) argues, this redistribution of sensory connections between living bodies and technical archi- 
tectures is more than a computational network that simply processes information. Parisi (2009) conceptualizes these atmospheric networks as "technoecologies of sensation" which move seamlessly "between organic and inorganic matter" (192). Dynamically mediated streams of sensory data become diffuse and elemental, opening onto a massively distributed "worldly sensibility" rather than remaining tied to individual bodies as processers of information and perception (Hansen 2015). Within this new 'atmospheric' media studies, sensors take on a new figuration as elemental and distributed agential forces which are not reducible to anything that humans can directly sense, perceive, or know.

Electro-dermal sensors are prime examples of such 'atmospheric media.' Skin activity is always already happening, as an imperceptible and uncontrollable charge of electricity that quivers on the periphery of the body's surface (Piccolini \& Bresadola 2013; Platoni 2015). In Hansen's (2015) terms, these sensors feed-forward sensory data into consciousness, making perceptible another layer of experience that would ordinarily have remained at the level of infraindividual sensibility, or virtual non-consciousness. As Massumi (2002) notes, the skin is faster than signification, faster than representational consciousness. At this historical moment, EDA sensors are part of a growing genus of sensory technologies capable of traversing or smudging this gap between consciousness and sensation, giving us a glimpse of intensities that would otherwise be too fast to perceive.

\section{TECHNICAL MATTERS}

It's important to attend to the technicities of EDA sensors and data, since there are a large number of technical and algorithmic interventions that enable this technology. In our own experiments with these technologies, we worked with a software company called iMotions to develop a technical setup that can record up to seven EDA signals at one time, along with three video and audio feeds. Our system uses Shimmer-GSR units consisting of a digital sensor strapped to the wrist and two analogue electrodes which can be attached to the finger, foot, or back of the neck. The sensors work by calculating the differential of electrical activity as it passes between two electrodes connected to the fingers or other part of the body (see Figure 1). These electrical differentials are measured in microsiemens and are linked to microscopic variations in the skin's production of sweat, 
often said to reflect changes in preconscious affect. The raw EDA signal can be sampled at variable rates per second, ranging from 4 to $2000 \mathrm{~Hz}$, depending on the granularity of the data required. We tend to sample at $128 \mathrm{~Hz}$, which is recommended for high-quality data without exceeding the bandwidth for multiple signal outputs. These analogue samples are digitally packaged and transmitted from the wearables to a Mobile Workstation laptop via Bluetooth, and can be synchronized with video and audio recordings and other types of sensor data.

When the sensors are active and paired with the Workstation, the streams of data can be visualized in a 'live view' with the color of each stream corresponding with one of the sensors. If the sensor is active but not worn by a person, it will stream electrical noise. As soon as the electrodes make contact with two points of a live body (e.g., two fingers), the electrical circuit is completed, and the data stream smooths out into a variable series of peaks and troughs. The signal begins to surf! This notion of surf-

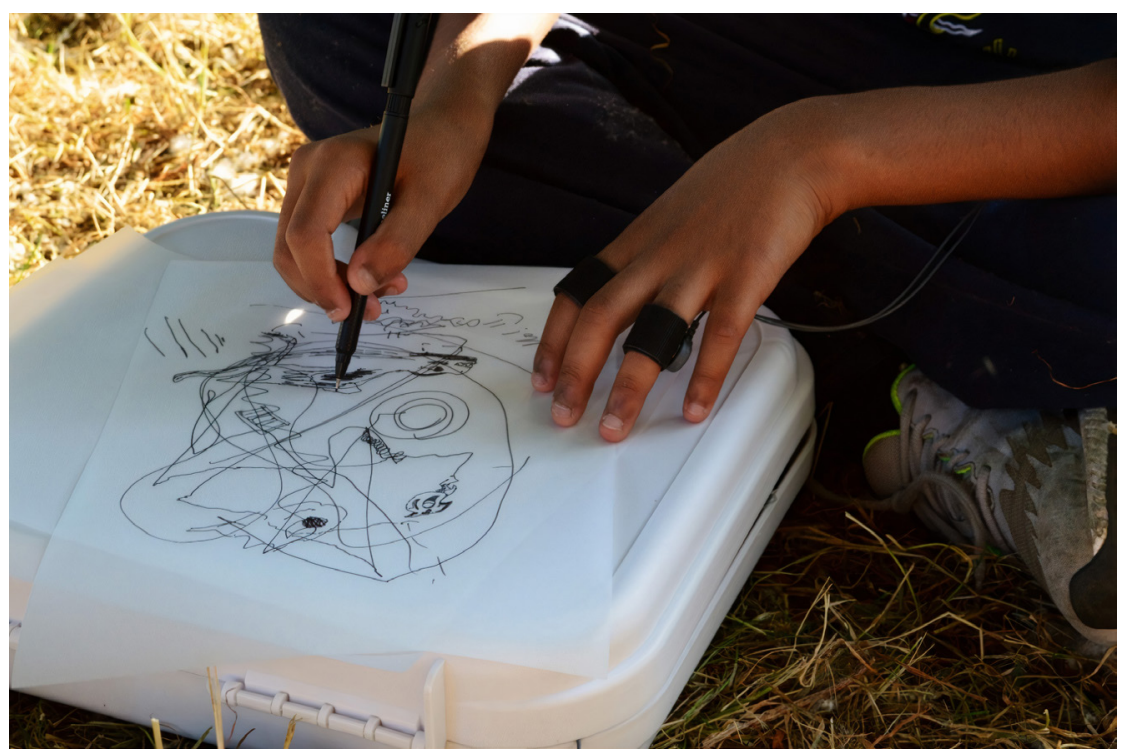

Figure 1. As part of an experiment with sensing place, children created an environmental installation and movement drawings in a local park while wearing EDA sensors. 


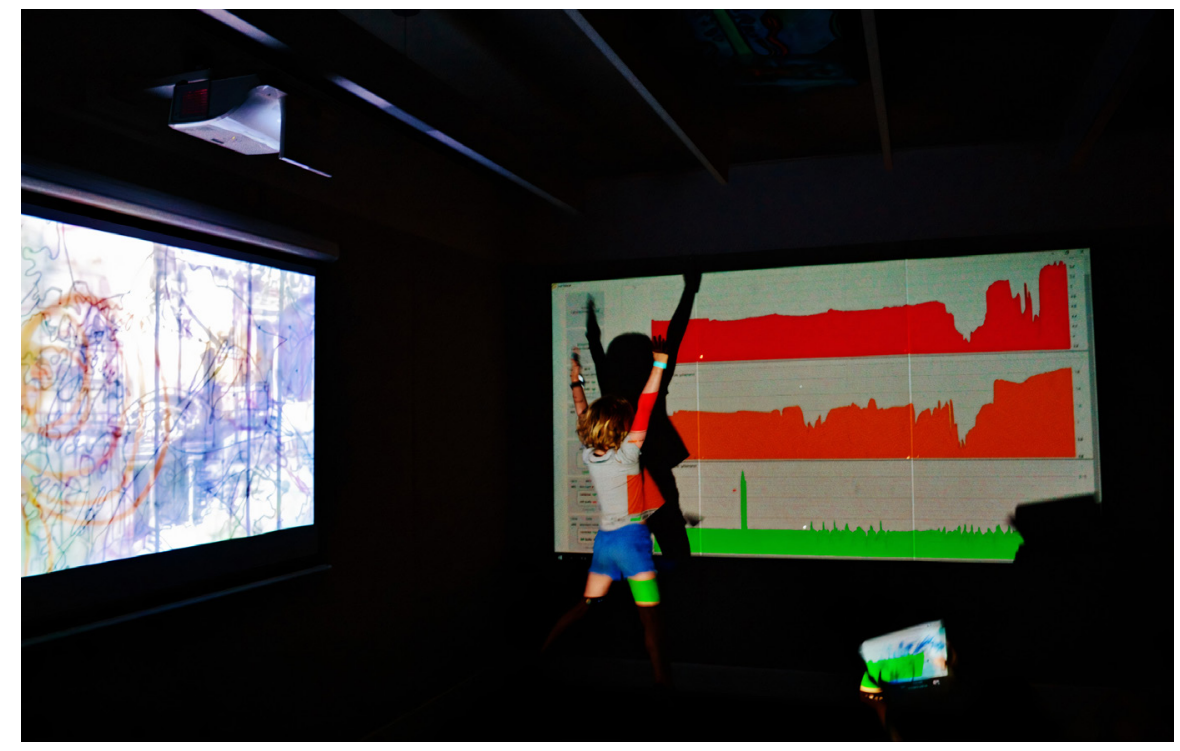

Figure 2. A young person experimenting with the live EDA data stream in the Superpositions (Rousell \& de Freitas) exhibition at Birley Art Gallery.

ing with the EDA signal was articulated by a child who attended one of our living lab exhibitions, an immersive environment that included collective experiments with live EDA projections (see Figure 2).

We mention these relatively simple examples to emphasize how the sensor plugs into and "makes visible" an affective intensity, movement, and charge of the body that is always already imbricated in socio-material ecologies. As we discuss further in the sections below, this capacity for sensor data from different bodies to "appear" public, as a group expression, opens up new possibilities for transindividual experimentations with modulation, resonance, synchrony, and disjunction across bodies. Remaining mindful of Massumi's (2002) noted gap between intensity and signification, we need to be careful not to collapse the "making visible" of the live data stream and the intensity that animates the moment.

In our EDA experiments with children and young people, iMotions software is used to process a live data stream of multiple EDA sensors and visualize the raw data as it is being collected from multiple signals in microsiemens. Algorithmic baselines and noise removal software 
are applied to the data, which is then processed to separate the raw EDA signal into two parts: the tonic signal and phasic signal. Cognitive scientists read the phasic signal as composed of EDA peaks associated with event-related response to stimulus. The phasic peaks are like little spikes of intensity, which are said to increase in amplitude and frequency when the sympathetic nervous system becomes aroused. The tonic signal, on the other hand, is associated with slow, adaptive responses to environmental changes. For instance, walking into a building often induces an adaptive response in the tonic signal as the body autonomously adjusts to changes in light, temperature, acoustics, and ambience. The tonic signal therefore suggests an atmospheric resonance between bodily, architectural, and climatological thresholds, perhaps akin to what Arakawa and Gins (2002) describe as an architectural body. Thresholds and doorways take on a certain importance with respect to the tonic signal as a register of felt transitions. Our research collective is interested in the tonic signal because it points at undergirding environmental conditions and atmospheric complexity. Many cognitive scientists dismiss the tonic signal because it cannot be indexed to a discrete internal event provoked by a discrete external stimulus. Most commercial applications of this technology are motivated by a desire to identify the potential shock value of particular images or ideas, and look only for the phasic signal. Our experiments, in contrast, attend to the tonic signals of multiple bodies as they gently drift, rise, and dissipate 'atmospherically,' falling in and out of synchrony in resonance with the environmental conditions through which an event is taking shape.

While the phasic signal registers distinct "peaks" of intensity that are typically correlated to distinct perceptions, the tonic signal registers more dispersed and durational transitions in the environmental field. Attending to this differential allows us to study the complex relations between environmental conditioning and the processing of micro-temporal sensibilities, and helps us theorize an atmospheric body. As de Freitas (2018) explains:

The fact that there is always this differential element to the electric body helps us theorize a body that is charged, but never static or still-bodies are related rates of change, each rate itself changing (change of change... ), involving second, third, and nth derivatives. The peripheral nervous system, extending the body into its frayed periphery, carries this charge in nonstop differentiated flows (300). 
Within the basic EDA signal there are also what are termed 'non-specific responses,' which refer to peaks for which no stimulus event can be determined. Although these are typically dismissed as noise because there is no apparent stimulus, we interpret these 'non-specific' responses as the rumblings of more widely distributed intensities of sensibility in the background. By studying the differential relations that undergird tonic and phasic elements of collective EDA signals, we seek to map the attunements, resonances, interferences, and disparities that structure a collective learning ecosystem. Rather than trying to quantify or measure intensity, we are using EDA sensors as agentive technologies that help to render the felt sense of an atmosphere that is always already recalibrating. We are interested in how the introduction of the sensors and the visualization of the live data alters the fabric of the atmosphere itself, showing how recursive or iterative affect feedback loops continue a process of multi-temporal differentiation that is always already going on.

\section{REMIXING THICK TIME: BECOMING A COLLECTIVE SENSING BODY}

Several of our experiments with atmospheric readings of EDA data have focused on shifting sensations of time within immersive gallery installations. These experiments were developed with a youth arts collective called the Young Contemporaries, a self-organizing group of young people aged 16-25 who meet weekly at the Whitworth Art Gallery in Manchester. Over a period of several months, our research team worked with the Young Contemporaries to develop a series of experimental propositions for sensing dynamic shifts and suspensions of time within William Kentridge's major exhibition Thick Time. Weaving together re-imagined histories of colonialism with the philosophy of art, cinema, science, and technology, Thick Time provided us with a rich environment of' timescapes' for developing sensory and creative experimentations with young people. The exhibition brought together five full-scale immersive artworks from Kentridge's collaborative oeuvre over the last ten years, including The Refusal of Time, Notes Towards a Model Opera, and O Sentimental Machine. Each of Kentridge's installations comprised a distinctive multi-sensory ecosystem, combining multi-channel sound, film, animation, sculptural, choreographic, and architectural components to condition a singular atmospheric experience in each space. 
While elsewhere we analyze the complex politics of participation in this project, attending to a decolonial ethics of opacity (Glissant 1997) and appositionality (Moten 2003) in urban gallery work (de Freitas et al. forthcoming), here we focus specifically on the use of EDA sensors and iMotions software to create intensive 'sense-mappings' of each of the five rooms in the exhibition. The invitation for young people to participate in this sense-mapping activity was framed around the proposition of 'becoming a collective sensing body.' This proposition drew on Manning's (2012) concept of the sensing body as a fielding of relational movements and potentials, where the body is posed "not as a stable category but as a creative vector of experiential space-time" (66). We began to think of Kentridge's Thick Time installations as environments for experimenting with the matrix of the sensing body in movement, as architectures where the environment itself becomes "an atmospheric body" (Manning 2021, 15). The proposition was elaborated further through theoretical engagements with young people around concepts of affect, intensity, sensation, and atmosphere. Members of the Young Contemporaries were also given the opportunity to discuss and problematize our theorization of the EDA sensors as atmospheric media, as well as our empirical understandings of skin conductance, the sympathetic nervous system, and embodied synchrony.

For one of our experiments, a group of five young people volunteered to wear EDA sensors and move as a collective sensing body through each of Kentridge's installations. We set up the Mobile Workstation running iMotions software in each of the exhibition spaces, functioning both as a recording instrument and a 20-inch interface for viewing the live sensor data. Three synchronized video feeds were captured from different points in each room, and high quality audio was rendered from head-mounted binaural microphones. The Workstation, as a live data interface, was placed in a visible location and quickly became another component of Kentridge's installations. In Kentridge's 0 Sentimental Machine installation, for instance, the live data interface sat on a table next to an old clock in an interior modelled from an early twentieth-century Turkish hotel lobby. By visualizing live EDA data in this location, intensity was folded back into the aesthetic atmosphere of colonial occupation conjured by Kentridge's exhibition, allowing us to actively view the emerging co-attunements 


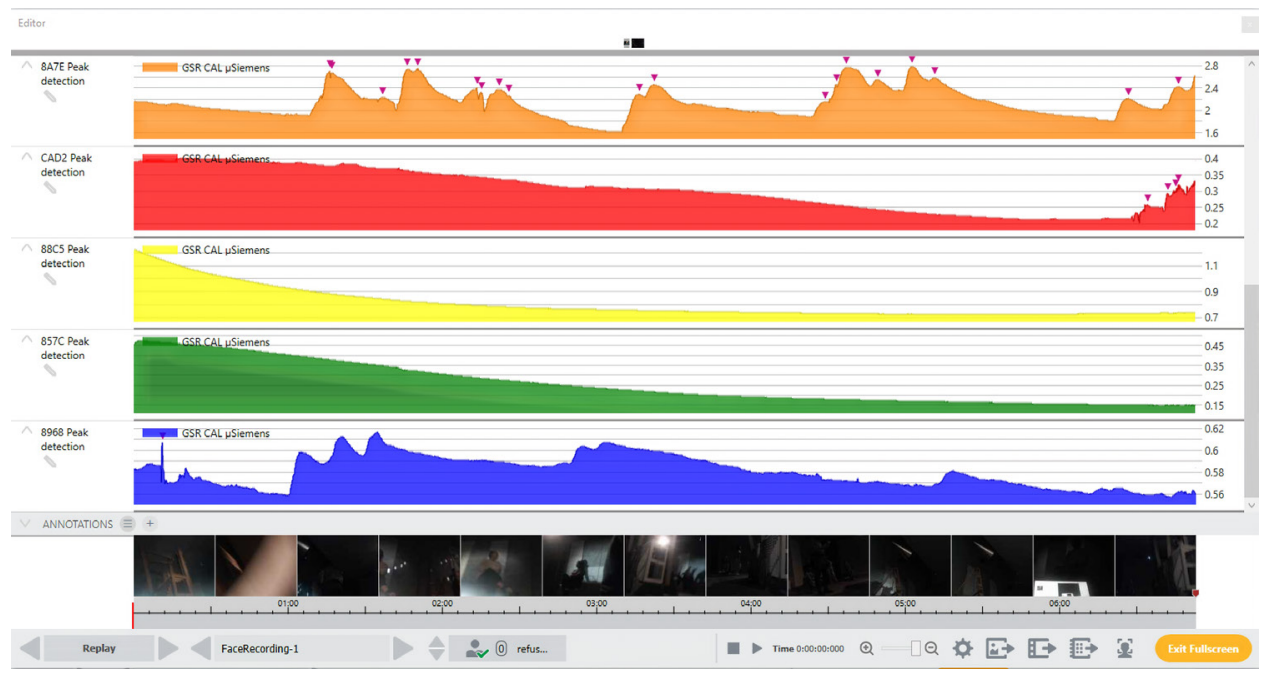

Figure 3. A six-minute recording rendered from five EDA sensors worn by young people in William Kentridge's immersive installation The Refusal of Time.

and disjunctions as they surfed across the physical screens in conjunction with the polytemporal movements and multi-sensory choreographics of Kentridge's work.

We spent around 15-20 minutes collectively sensing the atmosphere in each of the five spaces, often remaining quiet and simply listening, watching, feeling, sensing. Each of the rooms, filled with dynamic art and postcolonial testimony, became increasingly thick with shared affect. Afterwards the young people spoke about a palpable sense of 'togetherness' that emerged through this process, and a bodily sensitivity to the complex political landscape of Kentridge's art installation. Taking time to simply sense together opened up the complex temporality of the art installation, and seemed to offer a different form of collective sympathy. Rather than a collectivity built on dialogic interaction, the young people described a sense of thick temporal intensity, a sense of togetherness that was atmospheric and transindividual.

Figure 3 shows EDA data from a six-minute period of collective sensing in Kentridge's installation The Refusal of Time. The red, yellow, and green signals show a resonant "drift" toward dissipated EDA over the time recorded, with the yellow and green signals exhibiting the closest synchrony. The orange and blue signals show more variation, with some 
phasic peaks in the orange signal annotated by red arrows, but there is still a visible resonance between the movements of the two signals. While the numeric values on the right-hand side of the figure show that the five signals were 'surfing' at different degrees of intensity, our interest is in the relational rates of change in the signals, and the tendencies toward shared drifts of togetherness and disparity. We are interested in how intensive magnitudes of preconscious feeling drift together and apart within a charged atmosphere, without any imposed coordination or causal attribution of stimulus-response. The experiment entails no control or objective parameterization; it involves simply hanging out in what was an already charged political space. This underscores the molecular politics of galleries, where the field of experience is charged and potentialized with a multiplicity of variations and confluences (Deleuze \& Guattari 1987).

The data we present was recorded in a cavernous, dark gallery space with multi-channel video feeds covering all four walls. The cinematic content of the work included images of colonial violence and racial subjugation, the scientific and social fabrication of temporal regimes, animations of Kentridge's temporal experiments in the studio, and cosmic visualizations alluding to temporal multiplicity and Bergson's totality of images. Kentridge's installation also included multi-channel audio feeds relaying disparate sounds, chants, atonal music, and polytemporal rhythms through obliquely positioned megaphones, continuously altering the sonic fabric of the space. The middle of the room was occupied by a large kinetic breathing machine called 'the Elephant,' which maintained a consistent pulse of rhythmic activity in direct contrast with the shifting polyrhythms of the surrounding audio and video activity. During the recording of the data in figure 3, the five young people wearing the EDA sensors sat in an oblique formation surrounding the Elephant, which occluded their views of each other and the screens on the other side of the room. This created a situation in which none of the young people wearing the sensors were in apparent direct contact with each other, and none of them could see or hear the same thing. In other words, the young people were not 'interacting' or 'communicating' with one another in any conventional intersubjective sense, with each inhabiting a different 'region' of the environmental field that presented different sensorial dynamics. There were also many other kinds of movement and activity in the room, including other members of the Young Contemporary performing improvised movements with body cameras and haptic imaging techniques. We 
mention these details to highlight the polytemporal complexity of the sensory atmosphere in which the signals in figure 3 were recorded. Every square inch of Kentridge's The Refusal of Time was bombarding the body with a different rhythmic and sensorial texture and yet, somehow, bodies managed to collectively achieve a 'sympathetic intensity' through linked rates of change and dissipation. The collective drift toward tonic dissipation occurred within this disruptive and asynchronous sensory environment. The data from our experiment suggests that bodies can drift into sympathetic synchrony in the midst of a complex and dynamically changing environmental field, even when those bodies are not visibly interacting or focusing on a shared object or task.

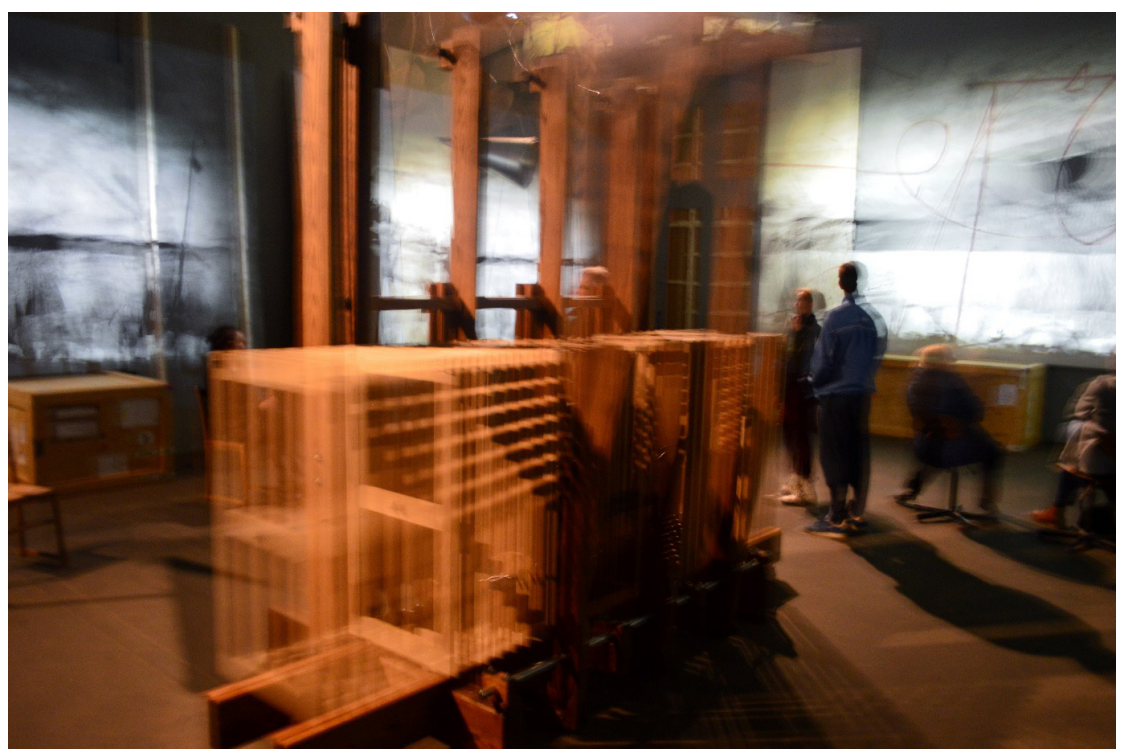

Figure 4. The Elephant in motion, from William Kentridge's The Refusal of Time at the Whitworth gallery, Manchester,UK.

\section{LINGERING THOUGHTS}

Our experiments engaged directly with the provocations of William Kentridge's Thick Time installation to consider sensibility outside the human-centric notion of perception, focusing instead on the realm of intensity and charged atmosphere (Clisby 2017; Colebrook 2014; Grosz 
2017). Accordingly, we treated biosensors as atmospheric vital media that both actualize and modulate intensity, making it 'appear' as contractions of affect across a charged field. These ideas bring us back to Massumi's (1995) analysis of skin conductance and intensity cited at the start of this chapter. If affective intensity is autonomous with respect to representational consciousness and perception proper, then perhaps it travels its own loops in what Simondon (2017) called at times "technicity" and at other times a "thought-network." These loops would betray classical spatio-temporal conventions of stimulus-response; we could imagine, for instance, a loop that discharges and recharges intensity through a complex mesh of connectivity. As Massumi claims, sympathy "can reverberate across a relational field, faster than the field of conscious calculation" $(2015,84)$. We have argued that this kind of amplification of intensity 'belongs' to the environment: "it is a defining characteristic of complex environments that the extremes of scale are sensitive to each other, attuned to each other's modulations. This is what makes them oscillatory. They can perturb each other" (Massumi 2015, 10).

Affectivity can 'channel' through the individual body, reverberating out to larger scales, as we begin to comprehend how an action or decision is "a doing done through us" (Massumi 2015, 20). Our interest in undertaking these experiments is not to establish a transparent, causal explanation for sympathetic synchrony, nor to induce or promote synchrony as a desired collective achievement. Rather, we are interested in how EDA sensors can help to create 'thick' experiential mappings of atmospheric events, bringing the infraindividual and microtemporal activity of the skin up to the level of transindividual sensibility and historical witness. Yet the tendency toward synchrony does present an important problem within this new empirical work, as it underscores the rapid viral transport of negative or positive affect without regulative reason or 'correction.' The co-presencing of skin activity achieves a sympathetic togetherness, a strange and discomforting intimacy of the non-conscious and the invisible. There are lingering questions around the normative thresholds of participating in sympathetic togetherness, and the relative ease or difficulty of crossing these thresholds for racialised and neurodiverse bodies (Manning \& Keupers 2018). This also raises political and ethical concerns regarding the possible manipulation or even 'mining' of collective intensity, or the induction of embodied synchrony for particular agendas. How do bodies modulate this sympathetic intensity, and how do we ensure that self-syn- 
chronizing collective events are generative of pluralism and diversity? Moreover, as we've discussed elsewhere (de Freitas, Rousell \& Jäger 2019), we must grapple with the ways in which biosensors are said to track the body's differential capacity for feeling, recapitulating racist and sexist investments in privileging or excluding certain bodies from "impressible corporeality" (Schuller 2018). Our interventions into the William Kentridge exhibition are intended to explicitly raise these concerns about which bodies are granted the political right to 'sense' and resonate affectively across thresholds.

\section{NOTES}

1. Electro-dermal skin activity (EDA) is also referred to as Galvanic skin response (GSR). We prefer the former because it emphasizes continuous activity rather than response to stimulus.

2. These experiments are funded by The Manifold Laboratory for Biosocial, Eco-Sensory and Digital Studies of Learning and Behaviour, at Manchester Metropolitan University. For more information visit https://www.biosocialresearchlab.com/ and https:// www.localalternatives.org/. We would like to acknowledge collaborators Laura Trafi-Prats and Riikka Hohti and the Whitworth Gallery Young Contemporaries for their essential role in these experiments.

\section{REFERENCES}

Banaee, H., Ahmed, M. U. \& Loutfi, A. (2013). Data Mining for Wearable Sensors in Health Monitoring Systems: A Review of Recent Trends and Challenges. Sensors 13 (12), pp. 17472-17500.

Clisby, D. (2017). Intensity in Context: Thermodynamics and Transcendental Philosophy. Deleuze Studies 11 (2), pp. 240-258.

Colebrook, C. (2014). Socially Invaded: The Biosocial Subject. Environment and Planning: Society and Space 32, pp. 556-570.

de Freitas, E. (2019a). Love of Learning: Amorous and Fatal. In: S. Bignalle \& R. Braidotti, eds., Posthuman Ecologies: Complexity and Process After Deleuze. London: Rowman and Littlefield, pp. 87-104.

de Freitas, E. (2019b). Digital Research Methods and Sensor Technologies: Rethinking the Temporality of Digital Life. In: J. Lynch, ed., Practice Methodologies in Education. New York: Routledge, pp.63-82. 
de Freitas, E. (2018). The Biosocial Subject: Sensor Technologies and Worldly Sensibility. Discourse: Studies in the Cultural Politics of Education 39 (2), pp. 292-308.

de Freitas, E. (2017a). The Temporal Fabric of Research Method: Posthuman Social Science and the Digital Data Deluge. Research in Education 98 (1), pp. 27-43.

de Freitas, E. (2017b). Non-Human Findings From the Laboratory of Speculative Sociology. Minnesota Review 88, pp. 116-126.

de Freitas, E., Rousell, D. \& Jäger, N. (2019). Relational Architecture and Wearable Space: Smart Schools and the Politics of Ubiquitous Sensation. Research in Education 107 (1), pp. 10-32.

de Freitas, E., Trafi-Prats, L, Rousell, D. \& Hohti, R. (forthcoming). A Poetics of Opacity: Towards a New Ethics of Participation in GalleryBased Art Projects With Young People. In: L. Trafi-Prats, R. Fendler \& A. Varela, eds., Becoming Lively in the City: Essays on the Ontology, Aesthetics and Ethics of Visual Participatory Arts-Based Research. London: Routledge, n.p.

Deleuze, G. (1994). Difference and Repetition. Translated by P. Patton. New York: Columbia University Press.

Deleuze, G. (1992). Postscript on the Societies of Control. October 59, pp. 3-7.

Deleuze, G. \& Guattari, F. (1987). A Thousand Plateaus: Capitalism and Schizophrenia. Translated by B. Massumi. Minneapolis: University of Minnesota Press.

Frost, S. (2016). Biocultural Creatures: Toward a New Theory of The Human. Durham: Duke University Press.

Galloway, A. \& Thacker, E. (2007). The Exploit: A Theory of Networks. Minneapolis: University of Minnesota Press.

Gillborn, D. (2016). Softly, Softly: Genetics, Intelligence and The Hidden Racism of the New Geneism. Journal of Education Policy 31 (4), pp. 365-388.

Glissant, E. (1997). Poetics of Relation. Translated by B. Wing. Ann Arbor: University of Michigan Press.

Grosz, E. (2017). The Incorporeal: Ontology, Ethics, and the Limits of Materialism. New York: Columbia University Press.

Hansen, M.B. (2015). Feed-Forward: On the Future of $21^{\text {st }}$ Century Media. Chicago: University of Chicago Press. 
Intel (2019). [online] Artificial Intelligence in Education. Available at: www. intel.com/content/www/us/en/education/transforming-education/ ai-in-education.html [accessed 26 January 2019].

Karvonen, A., Kykyri, V. L., Kaartinen, J., Penttonen, M. \& Seikkula, J. (2016). Sympathetic Nervous System Synchrony in Couple Therapy. Journal of Marital and Family Therapy 42 (3), pp. 383-395.

Lupton, D. (2014). Self-Tracking Cultures: Towards a Sociology of Personal Informatics. In: Proceedings of the 26h Australian Computer-Human Interaction Conference on Designing Futures: The Future of Design, 77-86. December 2-5. University of Technology, Sydney, Australia. New York: ACM, pp. 77-86.

Manning, E. (2012). Relationscapes: Movement, Art, Philosophy. Cambridge: MIT Press.

Manning, E. \& Keupers, H. (2019). How the Minor Moves Us Across Thresholds, Socialities, and Techniques: A Conversation with Erin Manning. [online] Open! Platform for Art, Culture, and the Public Domain. Available at: https://onlineopen.org/how-the-minor-moves-us-acrossthresholds-socialities-and-techniques [accessed 26 January 2019].

Massumi, B. (2018). 99 Theses on the Revaluation of Value: A Postcapitalist Manifesto. Minneapolis: University of Minnesota Press.

Massumi, B. (2002). Parables for the Virtual: Movement, Affect, Sensation. Durham: Duke University Press.

Massumi, B. (1995). The Autonomy of Affect. Cultural Critique 31, pp. 83-109.

Meloni, M. (2016). Political Biology: Science and Social Value in Human Heredity from Eugenics to Epigenetics. Basingstoke: Palgrave Macmillan.

Meloni, M., Williams, S. \& Martin, P. (2016). The Biosocial: Sociological Themes and Issues. The Sociological Review Monographs 64 (1), pp. 7-25.

Moten, F. (2003). In The Break: The Aesthetics of the Black Radical Tradition. Minneapolis: University of Minnesota Press.

Nafus, D. (2016). Quantified Self: Biosensing Technologies in Everyday Life. Cambridge: MIT Press.

Nold, C. (2009). Emotional Cartography: Technologies of the Self [online]. Available at http://www.emotionalcartography.net/ [accessed 26 January 2019].

Papoulias, C. \& Callard, F. (2010). Biology's Gift: Interrogating the Turn to Affect. Body and Society 16 (1), pp. 29-56. 
Parisi, L. (2009). Technoecologies of Sensation. In: B. Herzogenrath, ed., Deleuze/Guattari \& Ecology. Palgrave Macmillan, pp. 182-199.

Piccolini, M. \& Bresadola, M. (2013). Shocking Frogs: Galvani, Volta and the Electric Origins of Neuroscience. Oxford: Oxford University Press.

Platoni, K. (2015). We Have the Technology: How Biohackers, Foodies, Physicians and Scientists are Transforming Human Perception, One Sense at a Time. New York: Basic Books.

Protevi, J. (2013). Life, War, Earth: Deleuze and the Sciences. Minneapolis: University of Minnesota Press.

Rousell, D., Gallagher, M. \& Wright, M. (2018). Becoming Listening Bodies: Sound Walking as a Pedagogy of Sensation. Conference paper presented at the Third Conference on Arts Based and Artistic Research Tate Gallery, Liverpool.

Rousell, D. \& Fell, F. (2018). Becoming a Work of Art: Collaboration, Materiality and Posthumanism in Tertiary Visual Arts Education. International Journal of Education Through Art: Special issue on Speculative Realisms in Arts Education 14 (1), pp. 91-110.

Rousell, D. (2019). Walking with Media: Towards a Mixed Reality Pedagogy in University Learning Environments. In: H. Schnadelbach \& D. Kirk, eds., People, Personal Data, and the Built Environment. Netherlands: Springer, pp. 205-229.

Schuller, K. (2018). The Biopolitics of Feeling: Race, Sex, and Science in the Nineteenth Century. Durham: Duke University Press.

Simondon, G. (2017). On the Mode of Existence of Technical Objects. Translated by C. Malaspina \& J. Rogove. Minneapolis: Univocal.

Slovák, P., Tennent, P., Reeves, S. \& Fitzpatrick, G. (2014). Exploring Skin Conductance Synchronisation in Everyday Interactions. In: Proceedings of the 8th Nordic Conference on Human-Computer Interaction: Fun, Fast, Foundational, pp. 511-520.

Williamson, B. (2016). Digital Education Governance: Data Visualization, Predictive Analytics, and 'Real-Time' Policy Instruments. Journal of Education Policy 31 (2), pp. 123-141. 